\title{
A Regulatory Role for Large Vessels in Organ Circulation Endothelial Cells of the Main Renal Artery Modulate Intrarenal Hemodynamics in the Rat
}

Valentina Kon, Raymond C. Harris, ${ }^{*}$ and lekuni Ichikawa

With the technical assistance of Bradley R. Harvie and Laurette M. Hughes

Departments of Pediatrics and *Medicine, Vanderbilt University School of Medicine, Nashville, Tennessee 37232-2584

\begin{abstract}
After arterial denudation by external rubbing of the left main renal artery, we assessed renal plasma flow rate (RPF) and glomerular filtration rate (GFR) in left and right kidneys of Munich-Wistar rats before and after intravenous infusion of acetylcholine (ACH), atrial natriuretic peptide (ANP), or nitroprusside (NP). In the right kidney RPF and/or GFR increased in response to both endothelium-derived relaxing factor (EDRF)-dependent (i.e., ACH) and -independent vasodilators (i.e., ANP and NP); on average, RPF rose by $22 \pm 4 \%(P$ $<0.005), 19 \pm 10 \%(P<0.005)$, and $37 \pm 12 \%(P>0.05)$, respectively. By contrast, in the left kidney RPF failed to increase after ACH (falling by $23 \pm 10 \%, P<0.001$ ) and rose only in response to ANP and NP. To further evaluate the main renal artery's contribution to renal vasodilation, $\mathrm{ACH}$ and another EDRF-dependent agent, histamine, were infused through a micropipette into either the proximal or distal portions of the endothelium-intact renal artery. Proximal infusion of ACH led to increases in RPF and GFR, on average by $8 \pm 2 \%(P<0.025)$ and $10 \pm 3 \%(P<0.01)$, while bypassing the arterial endothelium by distal infusion failed to increase RPF and GFR, which fell by $24 \pm 6 \%(P<0.025)$ and $22 \pm 6 \%(P<0.005)$, respectively. Similarly, proximal infusion of histamine increased RPF by $12 \pm 3 \%(P<0.05)$, while distal infusion was virtually without effects on plasma flow. Micropuncture study during intravenous $\mathrm{ACH}$ infusion revealed significantly higher afferent and efferent arteriolar resistances and lower ultrafiltration coefficients in denuded versus nondenuded kidneys.

These data indicate that the main renal artery is a major regulator of renal blood flow and vascular resistances. Similar to other endothelium-derived substances, EDRF may be elaborated mainly by large vessels and may act on the downstream microcirculatory systems, which determine organ blood flow and transcapillary fluid transfer. (J. Clin. Invest. 1990. 85:1728-1733.) endothelium-derived relaxation factor $\bullet$ endothelial cells $\bullet$ renal artery $\bullet$ acetylcholine $\bullet$ glomerulus
\end{abstract}

This report was presented in part at the Annual Meeting of the American Society of Nephrology, San Antonio, TX, December 1988, and published in abstract form (1989. Kidney Int. 35:306. [Abstr.]).

Address correspondence to Dr. Valentina Kon, Assistant Professor of Pediatrics, Vanderbilt University School of Medicine, Nashville, TN 37232-2584.

Received for publication 8 May 1989 and in revised form 26 October 1989.

J. Clin. Invest.

(c) The American Society for Clinical Investigation, Inc. 0021-9738/90/06/1728/06 $\$ 2.00$

Volume 85, June 1990, 1728-1733

\section{Introduction}

The recent discovery of endothelium-derived relaxing factor (EDRF) $)^{1}$ has revolutionized the concepts underlying the regulation of vasomotor tone. Although its precise molecular structure is yet to be determined, EDRF participates in a variety of vasodilative phenomena. Thus, it is now recognized that many of the familiar vasoactive substances require the presence of intact endothelial cells to express all or part of their relaxation capacity. These substances include acetylcholine (ACH), bradykinin, histamine, thrombin, the calcium ionophore A 23187, ATP and ADP, substance P, and hydralazine (1-5). It has further been shown that physiologic vasodilation such as occurs in response to increased blood flow also requires endothelial cells and elaboration of $\operatorname{EDRF}(6,7)$. While some in vitro studies convincingly demonstrated that the endothelium of major arteries release EDRF, which acts on the underlying vascular muscles, others showed that EDRF could be transferred from one vascular strip to another and from one cellular preparation to another $(8,9)$, implying that EDRF formed by the endothelium of conduit vessels may act on downstream vascular beds distal to the site of its release.

The question of whether resistance-size vessels are capable of responding to EDRF has previously been addressed in in situ and in vivo studies using putative inhibitors of EDRF such as methylene blue, hydroquinone, hemoglobin, gossypol, and a light-dye technique that damages endothelial cells in portions of a vessel (10-14). In all but one of these studies (12) these inhibitors suppressed an increase in flow response or enlargement in vessel caliber in response to EDRF-dependent compounds. Although these studies are consistent with a role for EDRF in the regulation of vascular tone in microvessels, the methodology of perfusing the entire organ (i.e., both micro- and macrovessels) with inhibitors precluded localization of the source of the EDRF. It is of interest in this regard that manipulation of the main renal artery in in vivo experiments has been noted to result in a spontaneous fall in renal blood flow and/or failure to increase blood flow in response to known vasodilating substances (unpublished observations). These phenomena were unexplainable on the basis of conventional concepts regarding the main renal artery as a conduit vessel, which, unlike the microvessels, offers no resistance to axial blood flow. Since isolated segments of the renal artery can produce EDRF (15), it is possible that, in vivo, the main renal artery functions as an important source of EDRF, and the above noted phenomenon represents inadvertent damage to endothelial cells of this vessel.

1. Abbreviations used in this paper: $\mathrm{ACH}$, acetylcholine; ANP, atrial natriuretic peptide; EDRF, endothelium-derived relaxing factor; GFR, glomerular filtration rate; NP, nitroprusside; RPF, renal plasma flow rate; $\mathrm{SNGFR}$, single nephron glomerular filtration rate. 
In selecting an appropriate method for measuring the blood flow rate and renal vascular resistances in the current study, methodology was chosen which, in itself, does not impair the renal vascular endothelium, a requirement that excluded the flow probe method, widely used in various organ systems. In this regard, the kidney is unique among organs and vascular channels in that measurement of the rate of blood flow into the kidney and assessment of vascular resistances within the kidney can be obtained by collection of urine (clearance methods) or tubule fluid (micropuncture techniques).

Using these approaches we had an opportunity to test, in the renal circulation, whether endothelial cells of a large vessel can affect downstream resistance arterioles. Thus, we posed this question: Although the main renal artery offers no appreciable resistance to axial blood flow, do endothelial cells of the main renal artery produce sufficient EDRF to have a major impact on the tone of effector sites within the intrarenal microcirculation that regulate renal blood flow and glomerular filtration rate (GFR)?

\section{Methods}

Experimental protocols. All experiments were done in 30 male $\mathrm{Mu}-$ nich-Wistar rats weighing 187-296 g. The animals were allowed unlimited access to standard rat chow and tap water until the day of the experiment. At the time of the study the animals were anesthetized with Inactin (100 mg/kg body weight i.p.; BYK, Constance, FRG). A tracheotomy was performed and indwelling polyethylene catheters (PE-50; Clay Adams, Parsippany, NJ) were inserted into the femoral artery and vein and jugular vein for blood sampling, monitoring of systemic blood pressure, infusion of plasma, inulin, para-amino hippurate, and experimental vasoactive agents as previously described $(16,17)$. The mean systemic arterial blood pressure was measured by an electronic transducer (model p23Db; Gould Inc., Cleveland, $\mathrm{OH}$ ) connected to a recorder (model 2200S; Gould Inc.). The left kidney was exposed through midline and subcostal incisions. Both ureters were cannulated (PE-10). In addition, the left renal artery was gently isolated from the renal vein and the connective tissue, care being taken not to disturb the renal nerves and the lymphatics. To maintain the circulating plasma volume at a euvolemic level, each rat received isooncotic rat plasma, $10 \mathrm{ml} / \mathrm{kg}$ i.v. over $30 \mathrm{~min}$, followed by constant infusion at a rate of $1.2 \mathrm{ml} / \mathrm{h}(17)$.

In group 1A animals $(n=8)$ the contribution of endothelial cells of the main renal artery to the EDRF-dependent renal vasodilation was examined by whole kidney clearance. For this purpose, renal function was assessed in undisturbed kidneys and compared with the results from contralateral kidneys whose renal arteries were denuded of the endothelial cell layer (Fig. 1, top). Thus, before baseline measurements that included collection of urine from both kidneys and blood for determination of renal plasma flow rate (RPF) and GFR, the left main renal artery underwent endothelial denudation by renal artery rubbing, whereby the length of the left artery was externally rubbed by applying gentle pressure with a dissecting forceps that had its tips covered with PE tubing. It was found that only very gentle rubbing was required to denude the renal artery of its layer of endothelial cells. Fig. 2 is a section of the renal artery that was excised upon completion of the clearance studies, fixed in $10 \%$ buffered formalin, and processed for longitudinal sectioning and staining with hematoxylin and eosin. The top of the figure shows the nondenuded right main renal artery. Endothelial cells are indicated by the arrow. At the bottom of the figure is a section of the left renal artery that underwent denudation, showing absence of endothelial cells.

Following baseline measurements described above for an endothelium-dependent vasodilator, $\mathrm{ACH}$, was infused intravenously (12 $\mu \mathrm{g} / \mathrm{kg}$ per min; Sigma Chemical Co., St. Louis, MO), and after a 25min equilibration period renal clearance measurements and collec-

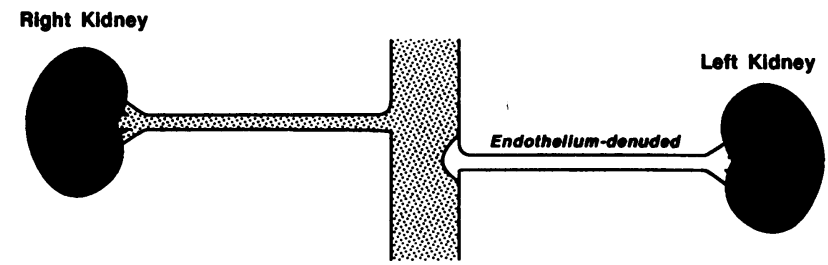

\begin{tabular}{|c|c|c|c|c|}
\hline $\begin{array}{c}\text { GR } \\
+9 \pm 5 \% \\
+13 \pm 6 \% \\
-22 \pm 378\end{array}$ & $\begin{array}{c}R P F \\
+22 \pm 4 z^{*} \\
+19 \pm 10 z^{*} \\
+37 \pm 128\end{array}$ & $\begin{array}{l}\text { Agent } \\
\text { ACH } \\
\text { ANP } \\
\text { XRP }\end{array}$ & $\begin{array}{c}\text { GrR } \\
-10 \pm 11 z^{*} \\
+35 \pm 88^{*} \\
+57 \pm 268^{*}\end{array}$ & $\begin{array}{c}\text { RPF } \\
-23 \pm 108 \\
+29 \pm 48 \\
+20 \pm 418\end{array}$ \\
\hline
\end{tabular}

Figure 1. Schematic illustration of the experimental manipulation for group 1A. Top, Endothelial denudation of the left main renal artery; bottom, comparison of the percent change from baseline values in renal hemodynamics in undisturbed right kidneys and the contralateral denuded left kidneys in response to systemically infused endothelium-dependent and -independent substances. ${ }^{*} P<0.05$.

tions were repeated. In some animals $(n=6) \mathrm{ACH}$ was stopped and after $30 \mathrm{~min}$ an endothelium-independent vasodilator, atrial natriuretic peptide (ANP), was infused intravenously $(70 \mathrm{ng} / \mathrm{kg}$ per min; Peninsula Laboratories, Inc., Belmont, CA). Measurements were obtained 20 min later. Another endothelium-independent dilator, sodium nitroprusside (NP; 3-5 $\mu \mathrm{g} / \mathrm{min}$ ) (Elkins-Sinn Inc., Cherry Hill, $\mathrm{NJ}$ ) was infused intravenously into three group 1A rats. To test if prostaglandins contribute to the vasodilating effects of $\mathrm{ACH}$, a separate group of rats with undisturbed kidneys, group 1B $(n=4)$, were treated with indomethacin $(3 \mathrm{mg} / \mathrm{kg}$ bolus followed by a constant infusion with $3 \mathrm{mg} / \mathrm{kg}$ per h; Sigma Chemical Co.) and then infused with $\mathrm{ACH}$ as described above with renal clearance measurements obtained before and after $\mathrm{ACH}$.
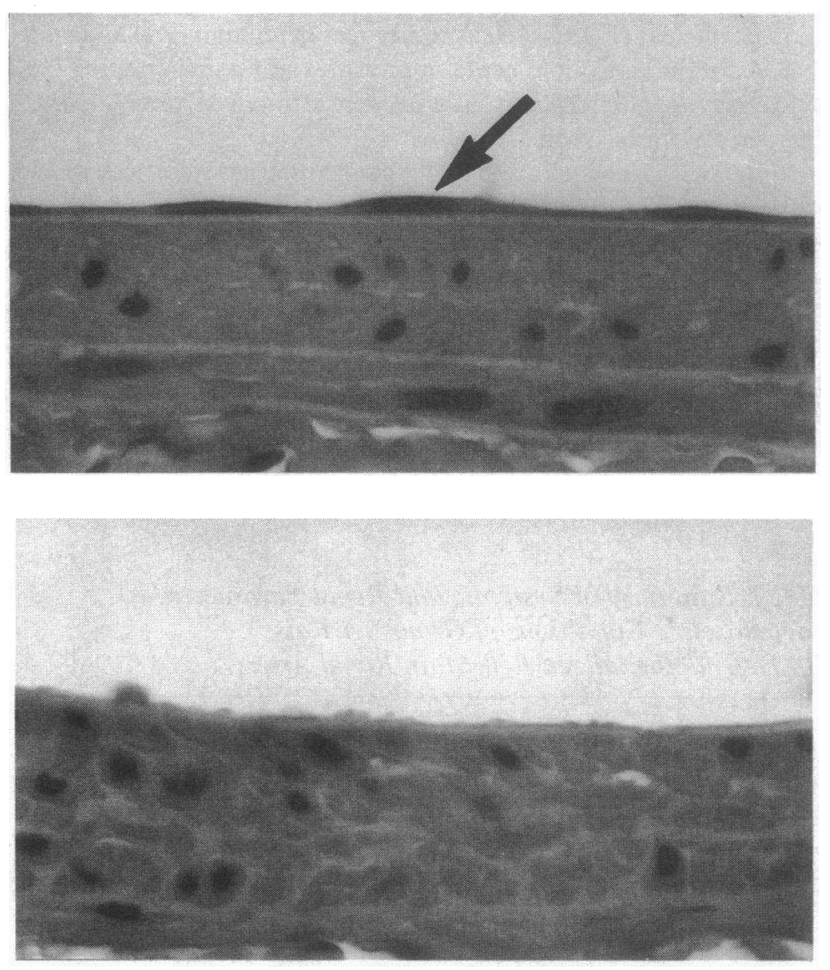

Figure 2. Sections of normal undisturbed right main renal artery (top) and denuded left main renal artery (bottom). Arrow, Endothelial cell nuclei. $\times \mathbf{4 5 0}$. 
Another experimental method was applied to examine further the role of endothelial cells of the main renal artery. In group $2 \mathrm{~A}$ animals ( $n=6)$ we compared the effects of ACH $(5.7 \mu \mathrm{g} / \mathrm{h})$ on renal hemodynamics when it was infused through a glass micropipette from the most proximal portion of the main renal artery versus infusion from the distal portion of the main renal artery, effectively bypassing a large portion of the main renal artery (Fig. 3). The route of administration was in random order. The infusion was accomplished through a sharpened micropipette having an opening of $20-30 \mu \mathrm{m}$, mounted to a micromanipulator and connected by $P E$ tubing to a syringe microinfusion pump (model 901; Harvard Apparatus Co., Inc., South Natick, MA) (14). The pipette was advanced through the wall of the renal artery and the infusion continued at a rate of $0.6 \mathrm{ml} / \mathrm{h}$. The infusion pump was calibrated in vitro as previously described by us (18). Blood and urine samples for subsequent determination of GFR and RPF were obtained during each of these proximal and distal infusions. In another group of rats (group $2 \mathrm{~B}, n=6$ ) the identical technique was applied to test another EDRF-dependent substance, histamine (1.5 $\times 10^{-5} \mathrm{M} / \mathrm{h}$ per $\mathrm{kg}$ body weight) (19).

Group 3 animals $(n=6)$ were studied to localize the effector loci for EDRF within the downstream renal resistance vessels. For this purpose, micropuncture measurements were obtained during systemic infusion of $\mathrm{ACH}(12 \mu \mathrm{g} / \mathrm{kg}$ per min) before and after renal artery denudation as described for group $1 \mathrm{~A}$. To determine single nephron GFR (SNGFR), measurements and collections were made by techniques previously described in detail $(16,17,20)$. Briefly, timed $(1-2$ min) samples of fluid were collected from surface tubules from each of two or three nephrons for determination of fluid flow rate and inulin concentration. The rate of fluid collection was adjusted to maintain a column of polymer oil, three to four tubule diameters in length, in a constant position just distal to the site of puncture. Coincident with tubule fluid collection, femoral arterial blood samples were obtained for determination of hematocrit and plasma inulin concentration. Hydraulic pressures in glomerular capillaries $\left(\mathrm{P}_{\mathrm{GC}}\right)$, tubules $\left(\mathrm{P}_{\mathrm{T}}\right)$, and efferent arterioles, as well as the femoral arterial $\left(C_{A}\right)$ and efferent arteriolar $\left(C_{E}\right)$ plasma protein concentrations were made, which permitted calculation of glomerular plasma flow rate $\left(\mathrm{Q}_{\mathrm{A}}\right)$, transcapillary hydraulic pressure difference $(\Delta \mathrm{P})$, and glomerular capillary ultrafiltration coefficient $\left(K_{f}\right)$, as well as resistances of afferent $\left(R_{A}\right)$ and efferent $\left(R_{E}\right)$ arterioles. Colloid osmotic pressures of plasma entering $\left(\pi_{A}\right)$ and leaving $\left(\pi_{E}\right)$ glomerular capillaries were estimated from $C_{A}$ and $C_{E}$ using derivations of Deen et al. (21).

Analyses. Plasma and urine inulin concentrations were determined by the macroanthrone method (22) and para-amino hippurate by the method of Bratton and Marshall, modified by Smith et al. (23). The volume of fluid collected from individual proximal tubules by micropuncture study in group 3 was estimated from the length of the fluid column in a constant bore capillary tube of known internal diameter. Details of the analytical procedure for inulin determination in nanoliter samples and $C_{A}$ and $C_{E}$ analyses are described elsewhere (21). Urine PG measurements were carried out by measuring a stable me- tabolite of PG, 6-keto-PGF $F_{1 \alpha}$ in urine during proximal and distal infusion of histamine (group 2B). Urine samples were collected in the presence of indomethacin and samples stored at $-70^{\circ} \mathrm{C}$ until assay. 6-keto-PGF ${ }_{1 \alpha}$ was determined by RIA (DuPont NEN Research Products, Boston, MA) after suitable dilution (1:10-1:25) in RIA buffer. The specificity of the antiserum used in these RIAs has been previously established (24).

Statistics. Results are expressed as mean \pm SE. Differences between the two periods in groups $1 \mathrm{~A}, 1 \mathrm{~B}, 2 \mathrm{~A}, 2 \mathrm{~B}$, and 3 were compared by paired $t$ test. Intergroup differences were tested by analysis of variance with Bonferroni's method (25). The results were taken as statistically significant when $P$ was $<0.05$.

\section{Results}

Table I summarizes the systemic and whole kidney parameters obtained in group 1A rats, which underwent de-endothelialization of the left main renal artery. The data presented are the baseline values obtained before infusion of endothelium-dependent or -independent vasoactive agents. As shown, before infusion of any vasodilators GFR was lower in the endothelium-denuded kidney $(P<0.05)$, and RPF was numerically, although not statistically, lower in these kidneys than in the contralateral endothelium-intact kidneys. In response to systemic infusion of $\mathrm{ACH}$ the blood pressure decreased, on average from $109 \pm 4$ to $98 \pm 3 \mathrm{mmHg}(P<0.001)$. Fig. 1 shows the responses of intact kidneys and kidneys that underwent endothelial denudation of the main renal artery to the endothelium-dependent vasodilator, ACH (group 1A). As can be seen in the figure, RPF increased in the intact right kidney, on average, by $22 \pm 4 \%(P<0.005)$, and GFR by $9 \pm 5 \%(P>0.05)$, responses similar to those reported previously (16). In striking contrast, in the denuded left kidneys of these same animals there was a directionally opposite response: RPF decreased, on average, by $23 \pm 10 \%(P<0.001)$ and GFR decreased by $10 \pm 11 \%(P<0.005)$. Although not shown in Fig. 1 , systemic infusion of indomethacin in rats with intact renal arterial endothelium, group 1B, did not lessen the degree of ACH-induced renal vasodilation. In these endothelium-intact animals GFR increased from $0.84 \pm 0.11$ to $1.34 \pm 0.13 \mathrm{ml} / \mathrm{min}(P$ $<0.05$ ) in the left kidney with ACH. The increase in RPF similarly was not blunted in response to $\mathrm{ACH}$ by treatment with indomethacin, rising by an average of $70 \%(P<0.025)$.

Also shown in Fig. 1 is the conspicuously different pattern in renal hemodynamics of group $1 \mathrm{~A}$ seen with the endothelium-independent vasodilator, ANP. ANP had no effect on the systemic blood pressure during RPF and GFR measurements.

Table I. Summary of Systemic and Renal Parameters under Baseline Conditions of Group 1A Rats with De-endothelialized Left Main Renal Artery

\begin{tabular}{|c|c|c|c|c|c|c|}
\hline \multirow[b]{2}{*}{ BW } & \multirow[b]{2}{*}{ AP } & \multirow[b]{2}{*}{ Het } & \multicolumn{2}{|c|}{ RPF } & \multicolumn{2}{|c|}{ GFR } \\
\hline & & & Right & Left & Right & Left \\
\hline$g$ & $\mathrm{mmHg}$ & vol\% & \multicolumn{4}{|c|}{$\mathrm{ml} / \mathrm{min}$} \\
\hline 218 & 109 & 43 & 2.53 & 2.41 & 0.85 & $0.75^{*}$ \\
\hline \pm 11 & 4 & 1 & 0.36 & 0.33 & 0.06 & 0.04 \\
\hline
\end{tabular}

Values are given as mean \pm SE. BW, body weight; AP, mean systemic arterial pressure; Hct, hematocrit. ${ }^{*} P<0.05$ between the kidneys.

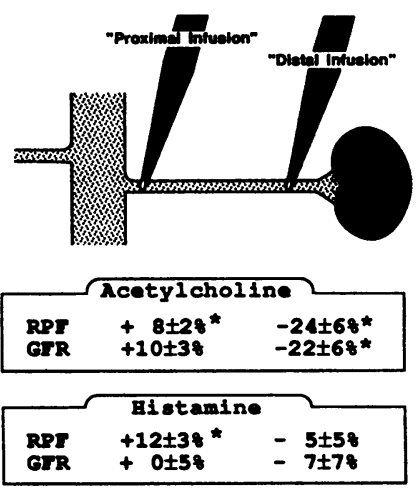

Figure 3. Top, Schematic illustration of the infusion technique originating from the most proximal and distal portions of the left main renal artery. Bottom, Comparison of the percent change from baseline values in RPF and GFR when $\mathrm{ACH}$ or histamine are infused from the proximal or distal portion of the main renal artery. ${ }^{*} P<0.05$. 
In the intact right kidneys there was, on average, a $19 \pm 10 \%$ increase in RPF $(P<0.005)$ and a $13 \pm 6 \%$ increase in GFR $(P$ $<0.005)$. In the denuded left kidneys this endothelium-independent vasodilator also significantly increased both RPF and GFR, on average by $29 \pm 4$ and $35 \pm 8 \%$. Another endotheliumindependent dilator, sodium NP, caused RPF to increase by $37 \pm 12 \%$ in the right kidney and $20 \pm 41 \%$ in the denuded left kidney, while GFR fell by $22 \pm 37 \%$ in the intact kidney and increased by $57 \pm 26 \%$ in the de-endothelialized left kidney.

The renal response to $\mathrm{ACH}$ (group 2A) or histamine (group 2B) infusion from different portions of the main renal artery were made within the same kidney and the results are shown in Fig. 3. During ACH infusion from the most proximal portion of the main renal artery in group $2 \mathrm{~A}$ rats, the systemic blood pressure decreased from $107 \pm 1$ to $104 \pm 1 \mathrm{mmHg}(P<0.05)$. Proximal ACH infusion caused both RPF and GFR to increase, on average by $8 \pm 2 \%(P<0.025)$ and $10 \pm 3 \%(P>0.01)$, respectively. When $\mathrm{ACH}$ was infused through the most distal accessible portion of the main renal artery, the blood pressure decreased from $109 \pm 2$ to $105 \pm 2 \mathrm{mmHg}(P<0.05)$. Renal hemodynamic patterns contrasting with those of proximal infusion of AEH were observed when $\mathrm{ACH}$ was infused through the distal site, bypassing the endothelium in the main renal artery: the endothelium-dependent $\mathrm{ACH}$ caused a reduction in both RPF and GFR, on average by $24 \pm 6 \%(P<0.025)$ and $22 \pm 6 \%(P<0.005)$, respectively.

A similar pattern was observed in a separate group of rats infused with histamine. Proximal infusion of histamine in group 2B caused an increase in RPF, on average by $12 \pm 3 \%(P$ $<0.05)$ above the baseline value, while histamine infusion through the most distal portion of the main renal artery was without significant vasodilating effects (Fig. 3). As previously observed (19), histamine did not alter GFR significantly when infused proximally or distally. The urinary excretion rate of a stable metabolite of PG, 6-keto-PGF ${ }_{1 \alpha}$, before any infusion of histamine averaged $161 \pm 35 \mathrm{pg} / \mathrm{min}$ and increased after proximal infusion of histamine to $226 \pm 45 \mathrm{pg} / \mathrm{min}(P<0.05)$. Despite absence of effects on renal hemodynamics, distal infusion of histamine was also associated with urinary excretion rates of 6-keto-PGF ${ }_{1 \alpha}$, which were significantly higher than baseline and averaged $274 \pm 57 \mathrm{pg} / \mathrm{min}(P<0.05)$.

To evaluate which downstream renal resistance vessels were influenced by the presence or absence of endothelial cells in the main renal artery, we measured preglomerular, glomerular, and postglomerular pressures and flows by micropuncture techniques (group 3). In endothelial cell-intact kidneys exposed to $A C H$ the $S N G F R$ averaged $38.8 \pm 6.6 \mathrm{nl} / \mathrm{min} ; \mathrm{Q}_{\mathrm{A}}$,
$134 \pm 27 \mathrm{nl} / \mathrm{min}$; and glomerular transcapillary hydraulic pressure difference $(\Delta P), 39 \pm 1 \mathrm{mmHg}$. During $A C H$ infusion in kidneys denuded of endothelial cells from the main renal artery these parameters were markedly different: SNGFR averaged $23.1 \pm 3.8 \mathrm{nl} / \mathrm{min} ; Q_{A}, 90 \pm 30 \mathrm{nl} / \mathrm{min}$; and $\Delta P, 36 \pm 3$ mmHg. $C_{A}$ was unaffected by the experimental manipulations, $5.4 \pm 0.2$ vs. $5.3 \pm 0.2 \mathrm{~g} / \mathrm{dl}$. Fig. 4 shows the values for the arteriolar resistances and ultrafiltration coefficients in these micropunctured rats. Both afferent and efferent arteriolar resistances were significantly higher in the denuded kidneys: $\mathbf{R}_{\mathbf{A}}$, $2.76 \pm 0.40 \times 10^{10}$ vs. $1.82 \pm 0.33 \times 10^{10} \mathrm{dyn} \cdot \mathrm{s} \cdot \mathrm{cm}^{-5}(P$ $<0.005)$; and $R_{E}, 2.00 \pm 0.19 \times 10^{10}$ vs. $1.64 \pm 0.27 \times 10^{10}$ dyn $\cdot \mathrm{s} \cdot \mathrm{cm}^{-5}(P<0.05)$. The glomerular capillary ultrafiltration coefficient, $K_{f}$, fell in every animal studied, on average from $0.053 \pm 0.016$ to $0.027 \pm 0.007 \mathrm{nl} /(\mathrm{s} \cdot \mathrm{mmHg})$ in kidneys in which the main renal artery was denuded.

\section{Discussion}

The observations that isolated rings and strips of large conduit vessels with damaged endothelial cell layers fail to respond to certain vasodilators known to relax vessel segments with intact endothelial layers is a phenomenon that has been demonstrated in virtually every artery tested in numerous mammalian species, including man $(1-10,26,27)$. This phenomenon is believed to involve EDRF. EDRF is now recognized to mediate the actions of numerous vasodilators, although not all vasodilative agents require EDRF to produce vasodilation. In the current in vivo experiments we physically denuded the left main renal artery of its endothelial cells and then assessed the effects of EDRF-dependent and -independent vasodilators on RPF and GFR in the left as well as the undisturbed right kidneys (Fig. 1). In the undisturbed right kidneys the RPF increased in response to systemic infusion of both EDRF-dependent $\mathrm{ACH}$ and EDRF-independent ANP. A contrasting pattern was seen in the endothelium-denuded left kidneys of the same animals: EDRF-dependent $\mathrm{ACH}$ led to a reduction in the RPF in denuded left kidneys. EDRF-independent ANP and NP increased RPF to a degree similar to or greater than the vasodilation in the right, nondenuded kidneys. A difference between intact and denuded kidneys in response to endothelium-dependent and -independent substances was also seen in GFR: while ANP increased GFR in both intact and denuded kidneys, $\mathrm{ACH}$ tended to increase in GFR in the intact kidneys, in contrast to the significant fall in GFR in the denuded kidneys. In response to NP, the value for GFR decreased numerically in the intact kidneys (presumably due to
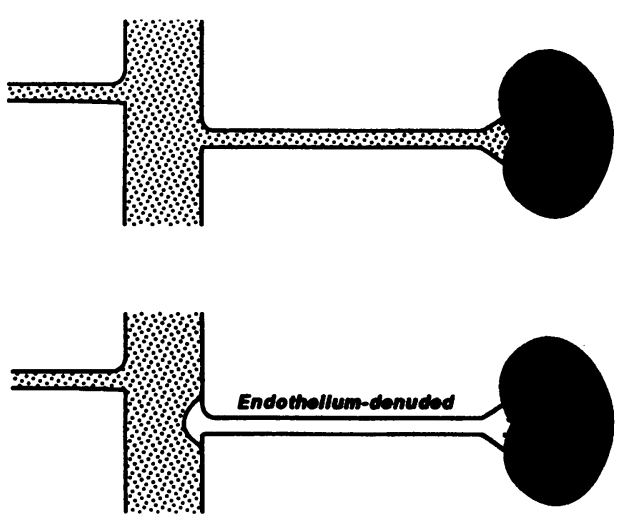

Figure 4. Schematic illustration of micropuncture data with and without denudation of endothelial cells from the main renal artery. 
depressed glomerular pressure) and increased in the left kidneys. Thus, as observed in in vitro studies with vascular strips by others (1-5), the current in vivo endothelial denudation of the left renal artery converted the otherwise vasodilative $\mathrm{ACH}$ to a vasoconstrictor. Of note, preservation of the intrinsic vasodilative ability of vascular smooth muscles of the denuded kidneys was confirmed in our study by the increase in RPF to the two EDRF-independent vasodilators, ANP and NP, which increased RPF in denuded kidneys.

The notion that the endothelium of the main renal artery is functionally important was further tested by examining the effects of $\mathrm{ACH}$ as well as another EDRF-dependent dilator, histamine, through a different experimental approach. Renal hemodynamics were compared when these substances were infused from the most proximal portion of the main renal artery versus the most distal accessible portion of the artery, effectively bypassing a large portion of the main renal artery (Fig. 3). This experimental design also circumvented the potentially confounding problem of stimulating release of endothelin and/or change in nerve traffic related to the denudation procedure. This is a consideration since our data as well as those of other investigators describe vasoconstriction after removal of endothelial cells. In response to proximal infusion of ACH, RPF increased significantly, while distal infusion of the EDRF-dependent ACH caused a reduction in both RPF and GFR. Likewise, only proximal and not distal infusion of histamine increased RPF. These experiments further support the idea that endothelial cells within the main portion of the renal artery are crucial for the vasodilative actions of $\mathrm{ACH}$ and histamine within the kidney. In addition, similar to recent in situ studies of rabbit lung (10) where experimental antagonism of EDRF reversed vasodilation to vasoconstriction, in our studies renal artery denudation changed ACH's typical renal vasodilative effect to vasoconstrictive action (Fig. 5).

$\mathrm{PGI}_{2}$ is one well-known vasodilator released from endothelial cells. Therefore, to exclude the possible contribution of PGs to the observed vasodilative actions of $\mathrm{ACH}$, indomethacin was given in a dose sufficient to inhibit a potentially important degree of endogenous $\mathrm{PGI}_{2}$ release (28). Systemic infusion of indomethacin did not modify the degree of ACH-induced increase in RPF in nondenuded kidneys. Furthermore, despite differences in renal vasodilation during proximal versus distal infusion of histamine, the urinary excretion of a

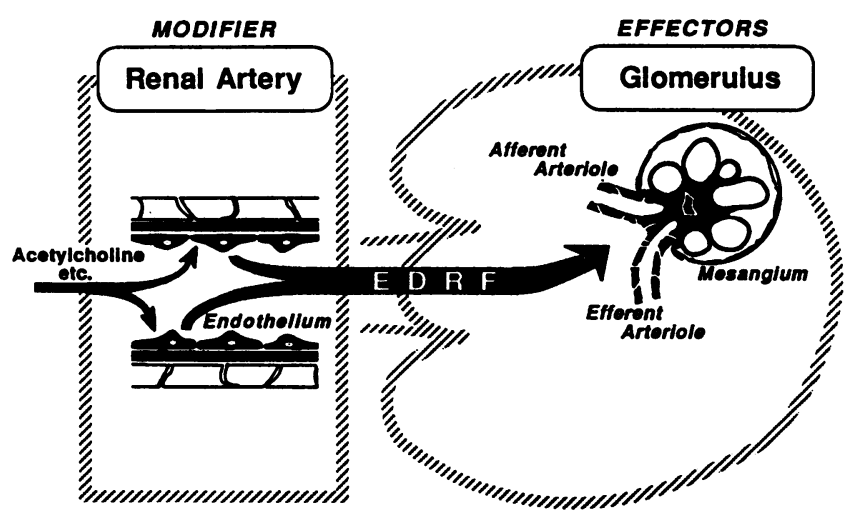

Figure 5. Proposed scheme for the role of endothelial cells of the main renal artery in modulating downstream glomerular hemodynamics. stable metabolite of PG, 6-keto-PGF ${ }_{1 \alpha}$, did not differ between these routes of administration. Collectively, the endotheliumdependent vasodilation appears largely independent of vasodilating PGs.

The notion that EDRF generated within the large vessel determines renal perfusion and filtration by acting on the downstream regulatory sites is in accord with the known characteristics of EDRF (Fig. 5). It is estimated that the half-life of EDRF is in the range of 6-60 s (28), which is well within the time necessary for blood to travel from the main renal artery to the glomerular microcirculation. Measurement of glomerular pressures and flows obtained in rats with and without endothelium denudation of the main renal artery during systemic infusion of $\mathrm{ACH}$ revealed that both afferent and efferent arteriolar resistances were higher and ultrafiltration coefficients lower in kidneys with endothelial denudation when compared with endothelium intact kidneys. These micropuncture measurements further strengthen the notion that EDRF derived from the main renal artery is capable of acting as a potent vasodilator of downstream resistance vessels, namely, afferent and efferent arterioles, and the glomerulus (i.e., $K_{\mathrm{f}}$ ), as well.

Given the current belief that the contractility of the mesangium, a structure interposing the glomerular capillary tuft, determines $K_{\mathrm{f}}$ by modulating the capillary filtering area, our micropuncture data suggesting the $K_{\mathrm{f}}$-raising effect of EDRF are also in agreement with recent in vitro experimental observations $(29,30)$. Thus, it has been shown that nitric oxide, a putative EDRF, added to the incubation media causes relaxation of and CGMP (intracellular miessenger for EDRF) generation by cultured mesangial cells (29). A recent preliminary report further strengthens the notion that EDRF derived from endothelial cells is capable of inducing these biochemical and morphological events in mesangial cells (30). These studies showed that the EDRF-dependent vasodilator, bradykinin, caused an increase in glomerular mesangial cell cGMP levels only in the presence of but not in the absence of endothelial cells $(29,30)$.

It is of interest that in the current study a comparable dose of $\mathrm{ACH}$ infused systemically caused greater renal vasodilation than infusion of $\mathrm{ACH}$ from the proximal portion of the renal artery. These findings raise the possibility that the aorta or other large vessels may be an even greater source of EDRF than the main renal artery. Our study also supports the possibility of substantial heterogeneity in EDRF production and/or endothelium-dependent response among different vascular beds ${ }^{2}$ and complements the recognized differences between endothelial cells in the microcirculation and endothelial cells in large vessels with respect to their morphology, growth char-

2. These data should not be taken as implicating the main renal artery as more important than intrarenal arteries in generating EDRFs that modulate resistance vessels. On the contrary, our data emphasize the importance of large vessels, particularly the renal artery, as functionally significant sources of EDRF without minimizing potential intrarenal sources. Thus, denudation of intrarenal endothelial cells, as well as those in the main renal artery, if technically possible, may result in greater renal vasoconstriction in response to $\mathrm{ACH}$. Similarly, infusion of $\mathrm{ACH}$ closer to the afferent arteriole may produce more vasoconstriction than observed in these in vivo experiments. The qualitative difference between endothelial cells of the large vessels versus those within the organ as a source of functionally significant EDRF remains to be determined. 
acteristics, and ability to elaborate other vasoactive substances (31-33). It is feasible, then, that within the renal circulation EDRF, which is primarily produced by the large conduit vessels (e.g., the aorta and main renal artery), acts as a vasodilator of resistance arterioles and mesangium (Fig. 5).

\section{Acknowledgments}

This work was supported by National Institutes of Health grants DK-39547 (to Dr. Kon) and DK-37868 and DK-37869 (to Dr. Ichikawa), and Veterans Administration Research Funds (to Dr. Harris). Dr. Harris is a Research Associate in the Career Development Program of the Veterans Administration. Dr. Ichikawa is a recipient of the Established Investigatorship Award from the American Heart Association.

\section{References}

1. Furchgott, R. F., P. D. Cherry, J. V. Zawadzki, and D. Jothianandan. 1984. Endothelial cells as mediators of vasodilation of arteries. J. Cardiovasc. Pharmacol. 6:S336-S343.

2. Young, M. A., and S. F. Vatner. 1986. Regulation of large coronary arteries. Circ. Res. 59:579-596.

3. Vanhoutte, P. M., and V. M. Miller. 1985. Heterogeneity of endothelium-dependent responses in mammalian blood vessels. $J$. Cardiovasc. Pharmacol. 7:S12-S23.

4. Furchgott, R. F. 1983. Role of endothelium in responses of vascular smooth muscle. Circ. Res. 53:557-573.

5. Furchgott, R. F., and J. V. Zawadzki. 1980. The obligatory role of endothelial cells in the relaxation of arterial smooth muscle by acetylcholine. Nature (Lond.). 288:373-376.

6. Kaiser, L., and H. V. Sparks, Jr. 1986. Mediation of flow-dependent arterial dilation by endothelial cells. Circ. Shock. 18:109-114.

7. Rubanyi, G. M., J. C. Romero, and P. M. Vanhoutte. 1986. Flow-induced release of endothelium-derived relaxing factor. Am. J. Physiol. 250:H1145-H1149.

8. Loeb, A. L., G. K. Owens, and M. J. Peach. 1985. Evidence for endothelium-derived relaxing factor in cultured cells. Hypertension (Dallas). 7:804-807.

9. Rubanyi, G. M., R. R. Lorenz, and P. M. Vanhoutte. 1985. Bioassay of endothelium-derived relaxing factor(s): inactivation by catecholamines. Am. J. Physiol. 249 (Heart Circ. Physiol. 18):H95-H101.

10. Cherry, P. D., and C. N. Gillis. 1987. Evidence for the role of endothelium-derived relaxing factor in acetylcholine-induced vasodilation in the intact lung. J. Pharmacol. Exp. Ther. 241:516-520.

11. Pohl, U., and R. Busse. 1987. Endothelium-derived relaxant factor inhibits effects of nitrocompounds in isolated arteries. $\mathrm{Am}$. J. Physiol. 252:H307-H313.

12. Griffith, T. M., D. H. Edwards, R. L. I. Davies, T. J. Harrison, and K. T. Evans. 1987. EDRF coordinates the behaviour of vascular resistance vessels. Nature (Lond.). 329:442-443.

13. Rivers, R. J., and B. R. Duling. 1986. Are the resistance vessels influenced by an endothelium derived relaxing factor (EDRF)? 70th Annual Meeting of the Federation of American Societies for Experimental Biology. 45:196.

14. Kaley, G., M. S. Wolin, and E. J. Messina. 1986. Endothelium-derived relaxing factors in the microcirculation. Blood Vessels. 23:81. (Abstr.)
15. Chaud, N., and B. M. Altura. 1981. Inhibition of endothelial cell-dependent relaxations to acetylcholine and bradykinin by lipoxygenase inhibitors in canine isolated renal arteries. Microcirculation. 1:211-223.

16. Kon, V., M. L. Hughes, and I. Ichikawa. 1983. Blood flow dependence of postglomerular fluid transfer and glomerulotubular balance. J. Clin. Invest. 72:1716-1728.

17. Ichikawa, I., D. A. Maddox, M. G. Cogan, and B. M. Brenner. 1978. Dynamics of glomerular ultrafiltration in euvolemic MunichWistar rats. Renal Physiol. 1:121-131.

18. Ichikawa, I. 1982. Direct analysis of the effector mechanism of the tubuloglomerular feedback system. Am. J. Physiol. 243:F447F455.

19. Ichikawa, I., and B. M. Brenner. 1979. Mechanisms of action of histamine antagonists on the glomerular microcirculation in the rat. Circ. Res. 45:737-745.

20. Kon, V., T. Yoshioka, A. Fogo, and I. Ichikawa. 1989. Glomerular actions of endothelin in vivo. J. Clin. Invest. 83:1762-1767.

21. Deen, W. M., J. L. Troy, C. R. Robertson, and B. M. Brenner. 1973. Dynamics of glomerular ultrafiltration in the rat. IV. Determination of the ultrafiltration coefficient. J. Clin. Invest. 52:1500-1508.

22. Fuhr, J., J. Kaczmarczyk, and C. D. Kruttgen. 1955. Eine einfache colorimetrische Method zur Inulinbestimmung für Nierenclearance-untersuchungen bei Stoffwechselgesunden und Diabetikern. Klin. Wochenschr. 33:729-730.

23. Smith, H. W., N. Finkelstein, L. Aliminosa, and B. Crawford. 1945. The renal clearance of substituted hippuric acid derivatives and other aromatic acids in the dog. J. Clin. Invest. 24:388-404.

24. Salmon, J. A. 1978. A radioimmunoassay for 6-keto-prostaglandin $F_{1 \alpha}$. Prostaglandins. 15:383-397.

25. Wallenstein, S., C. L. Zucker, and J. L. Fleiss. 1980. Some statistical methods useful in circulation research. Circ. Res. 47:1-9.

26. Angus, J. A., and T. M. Cocks. 1989. Endothelium-derived relaxing factor. Pharmacol. \& Ther. 41:303-352.

27. Tolins, J. P., R. M. Palmer, S. Moncada, and L. Raij. 1990. Role of endothelium-derived relaxing factor in regulation of renal hemodynamic responses. Am. J. Physiol. 258:H655-662.

28. Schor, N., I. Ichikawa, and B. M. Brenner. 1981. Mechanisms of action of various hormones and vasoactive substances on glomerular ultrafiltration in the rat. Kidney Int. 20:442-451.

29. Shultz, P. J., A. E. Schorer, and L. Raij. 1990. Effects of endothelium-derived relaxing factor and nitric oxide on rat mesangial cells. Am. J. Physiol. 27:F162-168.

30. Marsden, P. A., T. A. Brock, and B. J. Ballermann. 1989. Glomerular endothelial cells respond to calcium-mobilizing agonists with release of endothelium-derived relaxing factor. Clin. Res. 37:496A. (Abstr.)

31. Angus, J. A., T. M. Cocks, K. Satoh, and T. D. White. 1988. Receptor heterogeneity and EDRF release. In Sixth International Symposium on Vascular Neuroeffector Mechanisms. J. A. Bevan, H. M. Magewski, R. A. Maxwell, and D. F. Story, editors. IRL Press Limited, Oxford. 85-91.

32. Zetter, B. R. 1981. The endothelial cells of large and small blood vessels. Diabetes. 30(Suppl. 2):24-28.

33. Charo, I. F., S. Shak, M. A. Karasek, P. M. Davison, and I. M. Goldstein. 1984. Prostaglandin $I_{2}$ is not a major metabolite of arachidonic acid in cultured endothelial cells from human foreskin microvessels. J. Clin. Invest. 74:914-919. 